\title{
AS COMPETÊNCIAS DE GESTORES HOTELEIROS: REFLEXÕES ENTRE FORMAÇÃO E ATUAÇÃO PROFISSIONAL EM HOTELARIA NO BREJO PARAIBANO
}

THE COMPETENCIES OF HOTEL MANAGERS: REFLECTIONS BETWEEN TRAINING AND EXPERIENCE PROFESSIONAL IN HOTELS IN BREJO PARAIBANO

THALES BATISTA DE LIMA ${ }^{1}$ IELSEM DE SOUSA SINÉSIO

\begin{abstract}
RESUMO: A gestão por competências potencializa resultados nas organizações e desenvolve a qualidade das pessoas em que nelas trabalham. Na linguagem organizacional, isso é um "mix" de conhecimento, habilidades e atitudes que o indivíduo possui para estar adequado no desempenho de um cargo em uma organização. Nessa perspectiva, o artigo objetiva analisar esse conjunto de aptidões de gestores hoteleiros, localizados no brejo paraibano, a partir do que é descrito a esse respeito no Projeto Político Pedagógico do Curso de Graduação em Hotelaria da Universidade Federal da Paraíba. O estudo utilizou uma abordagem qualitativa, com o método dedutivo e descritivo sobre a percepção dos gestores. Assim, foi realizada uma entrevista semiestruturada com quatro gestores, cuja interpretação dos dados ocorreu por meio da análise compreensiva e interpretativa deles. Os resultados obtidos demonstram que a hotelaria do brejo paraibano, apesar de ter gestores com competências suficientes para conduzirem os meios de hospedagem que gerenciam, necessita de uma melhor condução sobre uma gestão por competência. É necessário qualificar o hoteleiro da região, sobretudo, com habilidades congruentes a de uma formação em Hotelaria, de maneira que atenda melhor ao contexto hoteleiro da região. Conclui-se que o fundamental para um profissional hoteleiro é possuir conhecimentos teóricos e práticos para que, em conjunto com os demais colaboradores, possam agregar valor social e econômico à organização.
\end{abstract}

PALAVRAS-CHAVE: Competências. Gestores Hoteleiros. Meios de Hospedagem.

ABSTRACT: The management by competencies increases results in organizations and develops the quality of the people in which they work. In organizational language, competence is a "mix" of knowledge, skills, and attitudes that the individual possesses to be adequate in performing a position in an organization. From this perspective, the article aims to analyze the skills of hotel managers located in the Brejo paraibano. The study used a qualitative approach, a descriptive and deductive method about the managers' perception. Thus, a semi-structured interview was conducted with four managers, whose interpretation of the data occurred through a comprehensive and interpretative analysis of the data. The results obtained demonstrate that the Brejo dairy industry, despite having managers with enough competences to manage the means of hosting that they manage, need a better management of competence management. It is necessary to qualify the hotelier of the

Data de submissão: 19/05/2017 Data de aceite: 19/05/2018 Data de publicação: 02/06/2018

1 Professor Adjunto do DCSA/UFPB

2 Graduado em Hotelaria 
region, above all, with competences congruent to that of a hotel training, in a way that better suits the hotel context of the region. It is concluded that, fundamental for a hotel professional is to possess theoretical and practical knowledge so that together with the other employees can add social and economic value to the organization.

KEYWORDS: Competencies. Hoteliers Managers. Means of Hosting.

\section{INTRODUÇÃO}

A gestão por competência é um método implantado nas organizações para melhorar em termos qualitativos a oferta de produtos e serviços, a fim de manter a fidelidade dos clientes e buscar novas oportunidades de mercado (RABAGLIO, 2008). Desse modo, essa gestão surge como uma ferramenta para alinhar habilidades humanas para a geração e a sustentação das características organizacionais necessárias ao alcance dos objetivos estratégicos da organização (CARBONE et. al., 2009).

Segundo Ruas (2001), as competências têm sido empregadas em três dimensões: as essenciais (mais abrangentes), que expressam a dimensão organizacional; as funcionais (aquelas inerentes ao desempenho das áreas vitais da organização), que têm dimensão de grupo; e as individuais (relativas às pessoas que atuam nas organizações). Esses desdobramentos de competências servem como auxílio para as organizações se manterem competitivas perante à concorrência e elevar seu nível de qualidade para atender a demanda mais exigente com os produtos e serviços que consomem.

Entretanto, aplicar gestão por competências nas organizações, de acordo com estudiosos e profissionais da área de Recursos Humanos, é conduzir os colaboradores para que possam atingir os objetivos da organização expressos em sua Missão, Visão e Valores (LEME, 2007). Neste sentido, Brandão e Bahry (2005) alegam que essa gestão tem sido apontada como um modelo gerencial alternativo que se propõe a gerenciar as lacunas de competências, reduzindo, assim, a desigualdade entre elas, as quais são necessárias à consecução dos objetivos organizacionais e àquelas já disponíveis no quadro funcional da organização.

Para Rabaglio (2008), a gestão por competência é uma metodologia utilizada nas organizações para impulsionar a qualidade de seus produtos e serviços e agregar valor a elas e aos seus colaboradores. Essa aplicabilidade só será possível se o conjunto de subsistemas da gestão por competência for bem planejado e executado por profissionais com conhecimentos teóricos e práticos, pois esse conjunto serve para fornecer todas as ferramentas necessárias para organizar os Recursos Humanos, tendo o perfil certo no lugar certo e investindo no desenvolvimento de competências necessárias para aumentar o nível qualitativo de seus colaboradores e, assim, podem-se obter resultados satisfatórios para a organização.

A mesma autora enfatiza que existem meios de se fazer gestão e desenvolvimento de pessoas com o foco em competências, entre eles está o mapeamento de competência, que é um método criterioso e organizado de identificação de habilidades necessárias para que a organização alcance suas metas e objetivos que, por meio de indicadores e avaliação de desempenho, os colaboradores se conscientizam da missão organizacional, mantendo o foco 
no propósito da organização. Essas qualidades tendem a melhorar se houver o treinamento e o desenvolvimento de competências de seus colaboradores. Essa ferramenta estimula o profissional a se qualificar na função que exerce atualmente e a desenvolver competências que futuramente poderá utilizar para o seu crescimento profissional (SPENCER; SPENCER, 1993; TRASATTI, 2005; MASCARENHAS, 2008).

Portanto, o profissional que estará se formando no curso de bacharelado em hotelaria precisa desenvolver certas competências para se adequar ao mercado de trabalho. Para aperfeiçoar a sua capacidade de empregabilidade, o indivíduo necessita desenvolver durante a sua formação acadêmica certos conhecimentos, habilidades e atitudes para se aproximar do mercado de trabalho, capacitado a trabalhar em qualquer setor dos meios de hospedagem. Além disso, ele pode se inserir em outros segmentos que derivam da área da hotelaria e do turismo, como, por exemplo: gastronomia, administração, entretenimento, controladoria, entre outros meios que podem empregar o profissional hoteleiro.

Dessa forma, é importante que os hoteleiros ingressem no mercado de trabalho com conhecimento teórico e prático para terem carreiras mais sólidas e com ampla oportunidade de empregabilidade, possibilitando agregar mais qualidade em seus métodos de trabalho e valor econômico para os hotéis. Por isso, este estudo contribui para um olhar atento à gestão de competências em gestores hoteleiros do Brejo paraibano, uma região da Paraíba que tem atraído a atenção dos turistas e de investidores do segmento turístico e hoteleiro, em virtude de suas belezas naturais e das cidades com arquiteturas históricas.

Entretanto, faz-se necessário um melhor planejamento e adequação dos investimentos e das políticas públicas voltadas ao Turismo nesta região brejeira, uma vez que a infraestrutura turística da região ainda é ofuscada pelos grandes centros paraibanos. Isso também é acentuado por conta da falta de inovação nas formas de produção de atividades turísticas da região, bem como da falta de aperfeiçoamento de gestores do ramo capazes de exercerem estilos de liderança focados na hospitalidade (LIMA; GOMES, 2017; RODRIGUES, 2017). Sendo assim, oeste artigo tem como objetivo analisar as competências de gestores hoteleiros, localizados no brejo paraibano, a partir das habilidades expostas no Projeto Político Pedagógico do Curso de Graduação em Hotelaria da Universidade Federal da Paraíba.

\section{AS COMPETÊNCIAS E SEUS DESDOBRAMENTOS}

Os estudos de Carbone (2009) relatam que, no final da idade média, a competência era atribuída a questões jurídicas, em que davam a alguém ou a uma instituição o discernimento de apreciar e julgar certas questões. Ao longo do tempo, esse contexto foi se estendendo àquelas pessoas que tinham o reconhecimento social e a capacidade de se pronunciar a respeito de assuntos com os quais tinham domínio. Em seguida, passou a ser utilizado também para indivíduos que eram capazes de desempenhar com qualidade funções em determinado trabalho. No século XX o termo competência passou a ser utilizado nas organizações para aqueles que obtinham eficiência naquilo em que trabalhavam.

Conforme esse mesmo autor, o termo competência passou a ser bastante aplicado na gestão organizacional, fazendo com que se criassem várias linhas de raciocínio sobre o tema, cujas mais fortes se destinavam aos autores norte-americanos (Boyatzis, 1982, e McClelland, 1973, por exemplo), que a entendem como um estoque de qualificação que possibilita uma pessoa a exercer um determinado trabalho. Por outro lado, os autores 
franceses (Le Boterf, 1999, e Zarifian, 1999, por exemplo) associam a competência não só as qualidades do indivíduo, mas sim no que ele produz ou realiza no âmbito organizacional.

Para Hanashiro et al (2007), os autores norte-americanos definem competência como inputs das pessoas, isto é, consistem em características que o indivíduo possui como conhecimento, habilidade e atitude, que afetam a habilidade individual para a performance. Já para os autores franceses, a competência são outputs, dimensões de fazer com iniciativa e responsabilidade, em determinado contexto, o que se sabe e conhece, mobilizando e integrando recursos pessoais.

Com base no ponto de vista dos autores norte-americanos e franceses, a competência está relacionada não apenas ao conjunto de conhecimento, habilidade e atitude, mas sim à versatilidade das pessoas em um contexto de comportamento e realização dessas atividades de forma eficaz, agregando valor social para si mesmo e valor econômico para a organização. Sendo assim, Carbone (2009, p. 43) as define como "combinações sinérgicas de conhecimentos, habilidades e atitudes, expressas pelo desempenho profissional dentro de determinado contexto organizacional, que agregam valor a pessoas e organizações". Portanto, se as competências humanas forem bem executadas pelo indivíduo, ocasionará benefícios para ele próprio e à organização em que está inserido, gerando lucratividade e bem-estar para ambas as partes.

No entanto, elas são desenvolvidas em quatro desdobramentos, que são: as Competências Individuais, as quais não estão limitadas apenas ao conhecimento do indivíduo e muito menos na atividade que ele exerce profissionalmente. Essa competência supera essas duas diretrizes, pois ela cresce em conjunto com o indivíduo no seu processo de aprendizagem durante o percurso de sua vida. Nesse sentido, Zarifian (1999) argumenta que tal competência é a inteligência prática para situações que se apoiam sobre os conhecimentos adquiridos e os transformam com tanto mais força, na medida em que aumenta a complexidade das situações.

As Competências Coletivas, podendo ser encontradas no nível organizacional e no nível funcional, na qual está associado tanto às atividades da organização como um todo, quanto à de suas áreas ou funções específicas (RUAS, 2005). De acordo com Zarifian (2008), é a organização que permite unir competência individual à coletiva. Para explicar essa afirmação, ele sugere alguns caminhos, sendo um deles a competência coletiva, que surge como resultado das interações sociais existentes nos grupos de trabalho da organização, e, por isso, significa mais do que a soma de habilidades individuais.

As Competências Gerenciais, conforme Ruas (2001), são a capacidade de mobilizar, integrar e transferir conhecimentos, habilidades e atributos, a fim de atingir ou superar desempenhos configurados nas atribuições, processo esse que se consolida apenas em situação de trabalho. Portanto, o indivíduo que for gerenciar uma organização ou um departamento deve colocar em prática essas competências para que elas possam auxiliá-lo no trabalho. Vale salientar que se elas não forem desenvolvidas no ambiente organizacional, acabam se tornando competências individuais.

E, por último, as Competências Organizacionais que, de acordo com Prahalad e Hamel (1997, p. 239), podem ser definidas como "uma articulação de recursos organizacionais, um aprendizado da organização, um saber-fazer coletivo e complexo, especialmente no que diz respeito à coordenação de diversas habilidades de produção e à integração de múltiplas correntes de tecnologia". Ou seja, é um conjunto de habilidades e tecnologias para agregar valores à organização que precisam da harmonia das competências 
individuais, coletivas e gerenciais e contribuem para o desenvolvimento estratégico e econômico da organização.

\section{A GESTÃO POR COMPETÊNCIAS}

De acordo com Levy-Leboyer (1997), a gestão por competências nas empresas é um assunto que nasceu no campo da psicologia organizacional, na década de 1990, quebrando o paradigma positivista empresarial na época. Para Dutra (2004), essa gestão tem sido uma alternativa aos modelos de administração para as organizações, ocasionando discussões acadêmicas e reflexões práticas entre os profissionais envolvidos em seu processo.

Muitas organizações utilizam a gestão por competência como uma forma de qualificar seus colaboradores para que juntos possam atender com eficácia a seus clientes e trabalhar de forma homogênea, buscando os mesmos objetivos, fortalecendo a organização em termos econômicos, qualitativos e mercadológicos. No entanto, Rabaglio (2008) enfatiza que a gestão aqui discutida é um conjunto de ferramentas práticas, consistentes e objetivas que torna possível para as empresas instrumentalizar a área de Recursos Humanos e Gestores, a fim de fazer a relação entre gestão e desenvolvimento de pessoas com foco, critério e clareza. Ou seja, a organização que faz uso da gestão por competência qualifica sua estrutura funcional, trazendo melhores resultados para ambas as partes (tanto para a empresa, quanto para seus colaboradores e clientes), sendo um diferencial no mercado em relação aos seus concorrentes.

Ainda, Mascarenhas (2008) explica que construir um sistema nesse tipo de gestão requer, inicialmente, a identificação das competências organizacionais mais relevantes à empresa para, então, derivar as habilidades funcionais e as individuais requeridas de seus membros.

\section{PERFIL DO HOTELEIRO}

Com a revolução técnico-cientifica, ou terceira revolução industrial e a globalização, as pessoas passaram a viver em um período de grandes inovações tecnológicas e mudança em seu estilo de vida, tendo uma maior necessidade de viajar e conhecer lugares novos. Esses dois acontecimentos mercadológicos estão interdependentes entre si, pois ambas são capazes de impulsionar uma à outra, promovendo mudanças econômicas, sociais e culturais que influenciam no modo como a humanidade analisa e age diante de vários aspectos comuns à sociedade (VESENTINI, 2005).

Segundo Moller (1999), entre as décadas de1950 e1970, os especialistas na área de qualidade priorizavam a qualidade dos produtos físicos. Após várias décadas é que se constataram melhorias da qualidade técnica, uma vez que houve o interesse pela qualidade dos serviços e pelo comportamento humano. Com essas mudanças no mercado, as organizações, tanto industriais, quanto as que trabalham com a oferta de produtos e serviços, que é o caso da hotelaria, começaram a investir no seu capital humano com treinamentos e desenvolvimento da qualidade de seus colaboradores, na qualidade de seus produtos e na satisfação dos seus clientes, e não só na quantidade da produção de suas mercadorias (CASTELLI, 2000).

As organizações que prestam serviços devem ter profissionais qualificados que se preocupem com a qualidade, tanto dos bens tangíveis, que são os produtos, mas principalmente dos bens intangíveis, que são os serviços (ZUANETTI, 2001). Desse modo, 
Castelli (2000, p. 39) alega que "a qualidade pessoal resulta, pois, do somatório das aptidões inatas de cada indivíduo e de todos os elementos a eles agregados através da educação e do treinamento. É esta qualidade que os empregados estarão reproduzindo no momento em que estão interagindo com os clientes". Ou seja, para atender as demandas de turistas e as mais avançadas tecnologias, os colaboradores da organização necessitam estar preparados e qualificados para que os clientes não se sintam insatisfeitos com os serviços prestados e, assim, possam fidelizar o seu público alvo e manter vantagem competitiva perante os concorrentes.

Tratando-se do campo a ser estudado por este trabalho, destaca-se que o curso de graduação em Hotelaria da Universidade Federal da Paraíba propõe-se a formar bacharéis com sólida formação geral e humanística, com capacidade e aptidão para compreender as questões científicas, técnicas, sociais, econômicas, empresarias e culturais relacionadas ao planejamento estratégico, à organização e à administração nos setores hoteleiros e extra hoteleiros. Adicionalmente, busca-se prepará-los para o gerenciamento específico, com observância dos níveis graduais do processo de tomada de decisão e com a assimilação de contínuas e novas informações emergentes do setor hoteleiro regional, nacional e internacional.

Outras qualidades de um prestador de serviços na formação de um perfil satisfatório às organizações hoteleiras já são destacados por Bolívar nos anos 1990 (1993): aprender a aprender e ter uma ampla formação cultural; ser criativo e inovador; estar consciente da ênfase que se deve dar a um serviço de qualidade e que o cliente é a pessoa mais importante; dominar perfeitamente todas as funções operacionais do setor; ser um profissional com suficiente conhecimento teórico-prático; possuir capacidade de trabalho; possuir conhecimentos tecnológicos atualizados e possuir conhecimentos de vários idiomas.

De acordo com a Organização Mundial de Turismo (1998), a formação do capital humano é primordial para as organizações de visão do setor turístico se manterem competitivas no mercado, sendo uma peça fundamental para as suas estratégias empresariais, podendo ser encontradas nos recursos humanos as fontes da criação do valor, da competitividade e da qualificação das organizações turísticas.

Portanto, com o avanço da tecnologia e com as novas exigências mercadológicas, os profissionais da hotelaria necessitam buscar atualização constante, saber línguas estrangeiras e atividades operacionais da profissão para estarem adequados ao mercado de trabalho e terem maior nível de empregabilidade. É preciso que os profissionais que são egressos da Universidade e se encontram iniciando no mercado hoteleiro tenham um conjunto de conhecimentos, habilidades e atitudes e estejam capacitados a exercer com eficácia a sua profissão e, assim, apresentem-se compatíveis ao perfil desejado pelas organizações para se firmarem no mercado de trabalho.

\section{METODOLOGIA}

O presente estudo teve como intuito analisar as competências de gestores hoteleiros localizados no brejo paraibano a partir das competências expostas no Projeto Político Pedagógico do Curso de Graduação em Hotelaria da Universidade Federal da Paraíba. Assim, a pesquisa pode ser caracterizada como uma abordagem qualitativa, na qual Oliveira (2008) define como uma tentativa de se explicar em profundidade o significado e as características do resultado das informações obtidas através de entrevistas e questões abertas, sem necessariamente a mensuração quantitativa de características e comportamentos. Nesse 
caso, buscam-se os significados encontrados nos gestores de hotéis no brejo paraibano no que se refere às suas competências em adequação com a formação acadêmica esperada por um hoteleiro.

O método utilizado foi o dedutivo, pois permite, segundo Cervo, Bervian e Silva (2007), construir estruturas lógicas por meio do relacionamento entre antecedente e consequente, hipótese e tese, premissas e conclusões. A pesquisa ainda se caracteriza como descritiva, que ocorre quando características de determinado fenômeno são expostas a ponto de estabelecer correlações entre suas variáveis e definir sua natureza (VERGARA, 2008). Portanto, o trabalho busca uma visão interpretativista dos dados coletados em campo para compreender melhor as nuances que envolvem a gestão por competências nos hotéis do brejo paraibano. Além disso, tem-se o objetivo de comparar a análise ora desenvolvida com as competências exigidas no Projeto Político Pedagógico do curso de bacharelado em Hotelaria da Universidade Federal da Paraíba, no intuito de entender mais a relação entre atuação e formação do profissional de Hotelaria.

A seguir, demonstra-se o perfil dos gestores hoteleiros entrevistados no brejo paraibano.

Quadro 1 - Perfil dos Gestores Hoteleiros do Brejo Paraibano

\begin{tabular}{|c|c|c|c|c|c|c|}
\hline Gestor & Gênero & $\begin{array}{c}\text { Faixa Etária } \\
\text { de Idade }\end{array}$ & Escolaridade & $\begin{array}{c}\text { Nível } \\
\text { Hierárquico }\end{array}$ & $\begin{array}{c}\text { Tempo no } \\
\text { Hotel }\end{array}$ & $\begin{array}{c}\text { Cargo Atual } \\
\text { CH1 }\end{array}$ \\
\hline Masculino & 31 a 45 anos & $\begin{array}{c}\text { Ensino } \\
\text { Médio } \\
\text { Completo }\end{array}$ & $\begin{array}{c}\text { Gestor de } \\
\text { Primeiro } \\
\text { Nível }\end{array}$ & 6 meses & 6 meses \\
\hline GH2 & Masculino & Até 30 anos & $\begin{array}{c}\text { Superior } \\
\text { Incompleto }\end{array}$ & $\begin{array}{c}\text { Gestor } \\
\text { Intermediário }\end{array}$ & 1 ano & 1 ano \\
\hline GH3 & Feminino & $\begin{array}{c}\text { Acima de } 45 \\
\text { anos }\end{array}$ & $\begin{array}{c}\text { Superior } \\
\text { Completo }\end{array}$ & $\begin{array}{c}\text { Gestor de } \\
\text { Primeiro } \\
\text { Nível }\end{array}$ & 4 anos & 4 anos \\
\hline GH4 & Feminino & 31 a 45 anos & $\begin{array}{c}\text { Superior } \\
\text { Completo }\end{array}$ & $\begin{array}{c}\text { Gestor de } \\
\text { Primeiro } \\
\text { Nível }\end{array}$ & 1 ano & 6 meses \\
\hline
\end{tabular}

Fonte: Elaboração Própria (2016).

Após a coleta dos dados, foi utilizada neste estudo a análise compreensiva e interpretativa deles (SILVA, 2005), pautando-se também na construção dos discursos em si. Dessa forma, as entrevistas foram gravadas nas datas previamente agendadas com os gestores e, em seguida, transcritas. Foi atribuída a sigla com as letras " $\mathrm{GH}$ " para os gestores hoteleiros entrevistados e, consequentemente, um número que se refere à sua identificação. Em seguida, seus discursos foram separados e codificados de acordo com a identificação do gestor entrevistado, seguido por um ponto e um número em sequência numérica e referente a um discurso relacionado a um assunto. Depois dessa separação e codificação, os discursos são classificados em categorias, com as quais se tem a finalidade de atender os objetivos da presente pesquisa.

\section{ANÁLISE E REFLEXÃO DOS DADOS}

A discussão dos resultados ocorre por meio das seis categorias a serem descritas abaixo: 


\subsection{Estratégias Organizacionais com foco em Competências}

As organizações, com o avanço tecnológico e o mercado competitivo, buscam estratégias mais efetivas para alavancar suas vendas e melhorar o padrão de qualidade dos serviços ofertados, que é o caso das hoteleiras. Essas estratégias são criadas normalmente pelos gerentes e proprietários dos meios de hospedagem, conforme explicam os gestores entrevistados nos discursos a seguir: "Na verdade, a rede que administra o hotel tem um gerente administrativo que é encarregado de criar essas estratégias, eu sou responsável por gerenciar a funcionalidade do hotel" (GH1.11). "As estratégias da pousada foram criadas por mim e pelo outro gerente" (GH2.11), "As estratégias foram implantadas por mim e os outros sócios, juntamente com um consultor muito importante quando fundamos o hotel" (GH3.12), “As estratégias foram criadas pelo proprietário" (GH4.13).

Quando questionados se eles tinham autonomia para modificá-las ou direcioná-las a partir de uma gestão por competências, as respostas foram as seguintes: "Temos que combinar com o diretor e os proprietários. Sempre que tenho alguma ideia estratégica para o hotel tenho que passar logo para eles e se eles aprovarem eu modifico e as aplico no hotel" (GH1.12), "Tenho total autonomia para modificá-las" (GH2.12), "A qualquer momento em que surgir uma estratégia melhor, eu tenho autonomia para modificá-las" (GH3.13), "Até um certo ponto temos autonomia sim quando as estratégias se referem à gestão da pousada, mas quando englobam a estrutura física, como, por exemplo, reformas, temos que comunicar ao proprietário e decidir se realmente iremos implantar essas estratégias" (GH4.14).

Contudo, os gestores GH1 e GH4 não fizeram parte da criação das estratégias organizacionais dos meios de hospedagem, como também não possuem total autonomia para modificá-las e direcioná-las por meio de uma gestão por competência. No entanto, os gestores GH2 e GH3 participaram da criação e implantação das estratégias e possuem tal autonomia.

Outro fator primordial para o desenvolvimento das estratégias organizacionais nos empreendimentos hoteleiros se refere à existência de uma gestão pautada nas competências dos colaboradores, cujos estudos de Carbone (2009) constatam que é um processo contínuo que tem como fase inicial a formulação da estratégia organizacional, contribuindo na qualidade dos auxiliares, com base na missão, visão e plano estratégico da empresa.

Seguindo essa perspectiva dos autores, os entrevistados, quando perguntados se há gestão pautada nas competências dos colaboradores, foram unânimes nas suas respostas: "Sim, pois a gente sempre está acompanhando o desenvolvimento de cada um deles, vendo como eles estão se saindo nas suas funções para quando surgir uma oportunidade de promoção na empresa possamos oferecer para o mais qualificado" (GH1.2). Dessa maneira, pode ser verificado também pelo discurso:

Atualmente sim, pois selecionamos pessoas que tem mais aptidão em uma área, como, por exemplo, na cozinha, quando temos eventos trazemos os melhores funcionários que demonstram certas capacidades para aquela área, como também na parte de serviços gerais, governança, rouparia e lavanderia, internamente nós fazemos essa divisão distribuindo os funcionários nas áreas onde eles têm mais habilidades (GH2.2).

O entrevistado GH3.2 relata em seu comentário que o nível de escolaridade de seus colaboradores é uma questão preponderante para que possam chegar a cargos de confiança 
e, assim, serem mais valorizados, como pode ser observado em seguida: "Sim, valorizamos os funcionários mais capacitados e aqueles que têm maior grau de escolaridade são designados a desempenhar funções mais complexas dentro do hotel e colocados em cargos de confiança e, assim, são bem mais remunerados". Já o gestor hoteleiro GH4.2, concorda com os demais de que há gestão pautada nas competências, mas que estipula metas para estimular os colaboradores a terem uma performance melhor, conforme a afirmação a seguir:

A gestão que fazemos aqui é pautada nas competências de cada um, pois estabelecemos metas a serem alcançadas aos funcionários e, ao longo das suas atividades, observamos se estão cumprindo essas metas com competência. Se estiverem, a gente retribui com elogios e homenagem do tipo funcionário do mês.

Dessa forma, os discursos dos gestores hoteleiros convergem no sentido de que a gestão realizada nos meios de hospedagem onde ocorreram as entrevistas é pautada nas competências dos seus colaboradores, mas que possuem metodologias diferentes umas das outras, o que também não significa nenhum demérito. Pelo contrário, são ferramentas estratégicas que visam o desenvolvimento organizacional da empresa e, consequentemente, a valorização de seus colaboradores.

Os indicadores reconhecidos pelos colaboradores se configuram como uma das ferramentas estratégicas que, de acordo com Leme (2005), é a melhor maneira de conduzir a gestão por competência para as organizações. Nesse sentido, dois dos quatro gestores entrevistados argumentaram que não possuem indicadores nos meios de hospedagem que gerenciam, ou não têm conhecimento sobre eles, conforme expressam as seguintes falas: "Infelizmente não temos indicadores" (GH1.9), "Não há indicadores aplicados na pousada" (GH2.9). Todavia, os gestores GH3 e GH4 falam dos que possuem, nos respectivos discursos:

Um indicador que temos no hotel é a missão do bem receber os hóspedes, então é fundamental para a gente, por isso, temos tantos cursos de capacitação e a gente já chegou a um nível que não recebemos nenhuma reclamação do bem atender, muito pelo contrário, recebemos só elogios, tanto pela internet, como pessoalmente. Esses indicadores são implantados no hotel por mim e mais outros gerentes com a ajuda do Sebrae e Senac (GH3.9).

Já o gestor $\mathrm{GH} 4$, fala do indicador de competências que possui a favor dos colaboradores como é descrito a seguir:

Um indicador que temos é a nossa filosofia de trabalho com os funcionários, pois damos oportunidade de crescimento para todos, por mais que seja uma pousada, mas essa valorização que temos com os funcionários é essencial para criar um clima de trabalho agradável (GH4.10).

Portanto, analisa-se que os meios de hospedagem em que os gestores $\mathrm{GH} 1$ e $\mathrm{GH} 2$ gerenciam não possuem indicadores de competência. Podemos indicar também que eles podem não ter esse conhecimento acerca desses indicadores. Por sua vez, os meios de hospedagem dos gestores $\mathrm{GH} 3$ e GH4 possuem tais indicadores que, segundo Rabaglio (2008), são todas as ações voltadas para o desenvolvimento estratégico da organização e niveladas na cultura organizacional, como, por exemplo: missão, visão, filosofia, valores, princípios, objetivos, entre outros.

\subsection{As Competências dos Gestores Hoteleiros do Brejo Paraibano}

Competências é algo que o indivíduo aprende naturalmente, tanto no convívio social com outras pessoas, como também em uma formação acadêmica, por exemplo. Tê-las em um cargo ou função dentro de uma organização significa possuir efetividade naquilo que lhe 
é atribuído. Para Rabaglio (2008), competências na linguagem organizacional são um conjunto de conhecimentos, habilidades e atitudes especificas para cada cargo que o indivíduo precisa ter para desempenhar a função que lhe é atribuída com qualidade. Nesse contexto, foi perguntado aos gestores hoteleiros se foram selecionados para tal cargo a partir de suas competências demonstradas no hotel.

Assim, seguem os discursos: "Na verdade, foi por conhecimento, pois os proprietários já conheciam o trabalho que eu fazia em outro hotel em Fortaleza, daí me convidaram para trabalhar aqui" (GH1.4), "Sim, pois quando vim trabalhar aqui foi na função de recepcionista, daí a proprietária viu minhas competências e meu esforço em melhorar os serviços da pousada e me promoveu para gerente" (GH2.4), "Na verdade, nós quatro somos os donos do hotel, então se a gente tá sendo os donos é porque temos capacidade para gerenciar o hotel" (GH3.4), "Sim, quando vim trabalhar aqui na pousada foi de recepcionista, daí mostrei as minhas qualidades e estou tentando me capacitar com cursos na área de hotelaria" (GH4.4).

Com isso, observa-se que os gestores $\mathrm{GH} 2$ e GH4 foram de fato promovidos pelas qualidades demonstradas nos meios de hospedagem em que gerenciam atualmente. Já o gestor GH1. foi escolhido para ser o gerente por ser conhecido pelos proprietários de outro trabalho que realizava em outro hotel, aparentando que este não costuma propiciar oportunidade de crescimento aos seus colaboradores. Por sua vez, o gestor GH3, como é um dos proprietários, não foi escolhido pelas suas competências, e, sim, dividiram entre eles o gerenciamento do hotel designando a conduzir o setor de venda em que tinha mais conhecimento para gerenciar.

Questionados sobre o que entendiam do termo "competências", o entrevistado GH1 segue em uma linha de raciocínio na qual a competência é o gestor saber colocar seus colaboradores em funções em que eles têm mais aptidão, como é demonstrado no discurso abaixo:

Cada pessoa tem a sua função e a gente vê o desenvolvimento de cada um. Tem pessoas que às vezes estão em funções que não são adequadas para essas pessoas, e não é porque eles não sejam competentes, é porque aquela função realmente não é adequada para aqueles funcionários (GH1.8).

Já os demais entrevistados, entendem competência como um saber para realizar as atividades com qualidade na organização, no intuito de satisfazer os clientes, conforme explicam nas afirmações a seguir: "No meu ponto de vista, competência é a habilidade junto com a responsabilidade para efetuar determinada atividade. Atualmente não aplicamos nenhum indicador na pousada" (GH2.8), "Competência é você saber desempenhar sua função no melhor que pode, atendendo as necessidades dos clientes" (GH3.8), "Eu entendo como competência a atitude, responsabilidade e comprometimento que temos naquilo que fazemos" (GH4.9).

Dessa forma, os gestores $\mathrm{GH} 2, \mathrm{GH} 3$ e GH4 conduzem a uma concordância com o entendimento de Carbone (2009) ao dizer que competência é uma sinergia de conhecimentos, habilidades e atitudes demonstradas dentro do ambiente organizacional, agregando valor às pessoas e à organização.

Outros discursos dos entrevistados, primordiais para identificar quais competências eles enxergam ter para exercerem um cargo de gestão hoteleira, são os seguintes:

Tenho um entendimento muito bom na área de restaurantes, como também com o ser humano, por exemplo, em dominar equipes. Tenho uma boa maneira de trazer o funcionário para a empresa e fazer com que ele trabalhe com gosto e dedicação, tornando um ambiente agradável dentro da empresa (GH1.13). 
O gestor $\mathrm{GH} 2$ também atribui uma das suas competências à criação de um ambiente agradável de trabalho no meio de hospedagem em que gerencia, como argumenta: "Liderança e organização, pois são competências essenciais para os gestores e é através delas que você irá conquistar os seus funcionários e criar um clima favorável dentro da empresa" (GH2.13). Já o entrevistado GH3, vê as suas competências na relação que têm com os colaboradores e hóspedes, como também a boa vendedora, visto em sua fala: "Eu sou boa em relações humanas e sou uma boa vendedora, por isso que sou gerente de vendas" (GH3.14). No entanto, o gestor hoteleiro GH4 vê suas competências atreladas à capacidade que conduz as situações difíceis, de acordo com seu discurso: "A capacidade de saber conduzir situações difíceis, como também atender bem os hóspedes e motivar os funcionários" (GH4.15).

Portanto, percebem-se, nos discursos dos gestores hoteleiros do brejo paraibano, competências adquiridas por uma formação acadêmica em hotelaria, mesmo não tendo formação nessa área. Em relação a isso, a fala do gestor $\mathrm{GH} 1$ revela que o seu conhecimento em hotelaria foi devido às suas experiências de vida e uma das demonstradas é a liderança da sua equipe de trabalho, criando um clima amigável, mas de respeito entre ele e os colaboradores.

Concordando com o gestor $\mathrm{GH} 1$, o gestor $\mathrm{GH} 2$ atribui a suas competências a liderança que tem em manter a pousada organizada para o conforto dos hóspedes. Por sua vez, o gestor GH3 evidencia que suas relações com os colaboradores e os clientes são boas, pois se denomina uma boa em relações humanas. Se de fato for o que realmente se diz ser, é uma competência essencial para o desenvolvimento do hotel e convívio social com sua equipe de trabalho.

Já o gestor $\mathrm{GH} 4$, atrela suas competências na capacidade que tem em saber conduzir as dificuldades da pousada, na motivação dos colaboradores, como também no bem receber os hóspedes. Como pode ser observado, o gestor GH4 possui competências semelhantes a dos outros gestores entrevistados, como, por exemplo, a liderança que exercem nos meios de hospedagem em que gerenciam. Esses discursos dos gestores do brejo paraibano seguem a perspectiva de Fleury e Fleury (2001), os quais definem competência como um saber agir responsável e reconhecido que implica mobilizar, integrar, transferir conhecimentos, recursos e habilidades, agregando valor econômico à organização e valor social ao indivíduo.

\subsection{Avaliação dos Gestores sobre as Competências dos Colaboradores}

A forma como os gestores avaliam a sua equipe de trabalho é fundamental para alcançar resultados satisfatórios e a qualificação de seus serviços. Portanto, eles, por meio de seus discursos, exprimem como é obtida essa avaliação a partir das observações realizadas: "Através da dedicação de cada funcionário, pois temos funcionários muito dedicados e o fundamental é eles gostarem do que fazem porque tem funcionário que faz as coisas com carinho e isso é muito importante" (GH1.7). "Apesar de não ter havido nenhum curso, os funcionários têm uma grande dedicação, procurando fazer os serviços da melhor forma possível, por mais que tenham algumas limitações e imprevistos, eles se esforçam para alcançar os objetivos da pousada" (GH2.7). E o gestor GH3 avalia através dos cursos que disponibiliza no hotel, pois a maioria dos colaboradores não possui um grau de escolaridade maior do que o ensino médio completo, observado no discurso abaixo.

Analisamos através dos cursos que oferecemos para os funcionários no hotel, pois a maioria que trabalha no hotel não tem a mesma escolaridade que eu e também 
não trabalhavam com hotelaria antes, então a gente precisa estar sempre se capacitando e qualificando os nossos funcionários (GH3.7).

$\mathrm{O}$ gestor hoteleiro $\mathrm{GH} 4$ avalia o desempenho de seus colaboradores de uma forma semelhante com os gestores $\mathrm{GH} 1$ e $\mathrm{GH} 2$, conforme a afirmação a seguir: "A gente delega uma função para os funcionários e eles resolvem, às vezes até mesmo sem precisar a gente falar, pois todos sabem da sua função e desenvolvem de forma satisfatória" (GH4.8).

Dessa maneira, os entrevistados, de acordo com Mascarenhas (2008), avaliam as competências dos colaboradores com métodos de avaliação do desempenho e não das competências, pois a avaliação do desempenho enfatiza o controle dos comportamentos dos indivíduos e a avaliação das competências é algo mais complexo que enfatiza a análise das capacidades dos indivíduos, como seus conhecimentos, habilidades e atitudes referentes ao trabalho em determinado contexto.

\subsection{Competências adquiridas por uma Formação Acadêmica em Hotelaria}

Segundo o PPP do curso de Graduação em Hotelaria da Universidade Federal da Paraíba, o trajeto deve possibilitar a formação profissional que revele competências e habilidades para atuar no planejamento, a implantação e no gerenciamento hoteleiro; adotar, com eficácia, modelos inovadores de gestão; manejar os recursos informatizados e outros equipamentos tecnológicos; exercer, com liderança e responsabilidade, o gerenciamento da unidade hoteleira, direcionado ao melhor atendimento ao cliente/usuário. Essas são umas das atividades que um Bacharel em Hotelaria deve exercer com competência para que possa gerenciar um empreendimento hoteleiro.

Quando perguntados se eles tinham conhecimento das competências adquiridas em uma formação acadêmica para exercer tais atividades, os gestores GH2, GH3 e GH4 falam que não tinham conhecimento, já o gestor GH1 falou que tinha um bom conhecimento, como demonstram nos discursos a seguir: "Tenho um bom conhecimento, atualmente se os hóspedes chegarem no hotel e não tiver WiFi, eles reclamam, então, temos que estar atentos ao mercado para ver sua modernização e, assim, tentar implantar essas inovações no hotel" (GH1.16), "Não tenho conhecimento das competências adquiridas por uma formação acadêmica em hotelaria" (GH2.16), "Como sou formada em outra área que não é a hotelaria eu não tenho conhecimento das competências exigidas pelo curso" (GH3.17). Por outro lado, o gestor $\mathrm{GH} 4$ em seu discurso argumenta não saber das competências adquiridas em uma formação, mas que elas podem ser aprendidas também na prática, como diz abaixo.

Eu não tenho conhecimento das competências exigidas por uma formação em hotelaria, mas acho que uma pessoa para ter competência em uma determinada função não precisa necessariamente ter uma formação, pois essas competências adquirimos com um tempo e experiência de trabalho (GH4.17).

Observa-se que os gestores $\mathrm{GH} 2, \mathrm{GH} 3$ e GH4 não possuem conhecimentos sobre as competências alcançadas por uma formação acadêmica em Hotelaria, mas que aprenderam com as experiências vividas ao longo de suas carreiras na hotelaria competências para desempenharem com efetividade o cargo que Ihes é atribuído. Em contrapartida, por mais que não tenha uma formação, o GH1 argumenta possuir conhecimento das competências adquiridas por uma formação acadêmica em Hotelaria, por ser um profissional experiente nesse ramo de trabalho. Tal visão vai ao encontro de seu discurso no qual expressa estar atento às inovações para que possa implantá-las no hotel com um dos aspectos do PPP do curso de Hotelaria: o de adotar com eficácia os modelos inovadores de gestão. 
Assim, esse relato está em conformidade com uma das qualidades que Bolívar (1993) acha importante para um profissional das organizações hoteleiras, que é ser criativo e inovador, possuindo conhecimentos tecnológicos atualizados. Essas qualidades resultam em uma maior satisfação dos hóspedes e na competitividade com os demais concorrentes. No entanto, os demais entrevistados não falam possuírem esse conhecimento das competências adquiridas por uma formação acadêmica em hotelaria, podendo ser uma desvantagem perante outros gestores que abdicam desse conhecimento teórico.

\subsection{A importância do Idioma na Hotelaria}

A hotelaria é um segmento turístico em que seus profissionais devem estar adequados à demanda mercadológica com qualidades individuais e coletivas, para que possam manejar com eficácia o meio de hospedagem em que estão inseridos, que, segundo Castelli (2000), são estes os atributos desenvolvidos por meio da educação e do treinamento, os quais passarão a colocar em prática no momento em que estão interagindo com os clientes. Por ser um segmento turístico que atende a um elevado fluxo de turistas que vêm do exterior, o hoteleiro necessita ter fluência em idiomas como o inglês e o espanhol, basicamente, por serem línguas mundialmente faladas. Nesse contexto, os gestores hoteleiros entrevistados foram questionados se tinham fluência em algum idioma e as respostas foram as seguintes:

Não falo, mas acho que seria importante porque no ramo da hotelaria tem muito turistas que vêm de fora do pais e se você não fala nenhum idioma acaba tornando a comunicação com o hóspede um pouco difícil, portanto é muito importante que o hoteleiro saiba falar pelo menos o inglês para não criar essas dificuldades com os hóspedes (GH1.19).

O entrevistado $\mathrm{GH} 2$ argumenta que não fala outro idioma, mas que seria importante, pois o meio de hospedagem que gerencia recebe turistas vindos do exterior, conforme o discurso a abaixo:

Não falo nenhum idioma a não ser o português, mas considero que seria importante, porque aqui na pousada vêm pessoas de outros países, como o Canada, Chile, Republica Dominicana, e se no meu caso eu tivesse uma fluência no espanhol ou inglês facilitaria muito na minha comunicação com esses hóspedes (GH2.18).

Já o gestor GH3, não apresenta domínio em outro idioma, entretanto, relatou que os outros gestores do hotel falam e que para o hoteleiro o idioma abre horizontes, como diz: “Eu não falo outro idioma, mas meus outros sócios falam. A língua é importante para o hoteleiro porque abre horizontes para ele" (GH3.19). No entanto, o gestor GH4 argumenta das dificuldades na comunicação com esses hóspedes e na facilidade quando vêm com os guias turísticos, como pode ser visto logo abaixo:

Não falo, mas considero que seria muito importante para um hoteleiro saber outro idioma, pelo menos o inglês, porque às vezes encontramos dificuldade na comunicação com estrangeiros quando vêm se hospedar na pousada, quando eles vêm com guia turístico a comunicação é facilitada, mas quando não vêm a comunicação é feita através de gestos (GH4.21).

Contudo, percebe-se que nenhum dos entrevistados do brejo paraibano fala outro idioma, a não ser o português, o que causa defasagem na comunicação dos mesmos com os hóspedes estrangeiros, restando aos gestores a comunicação por meio de gestos. Isso diverge de uma das atividades que o PPP do curso de Hotelaria aborda como necessária para 
o hoteleiro ter competência em se comunicar com os clientes em idiomas estrangeiros, principalmente, na língua inglesa e a espanhola.

\subsection{Relação entre Formação e Prática de um Hoteleiro}

A formação e a prática de um hoteleiro deveriam concordar em termos de concretização, pois em uma construção acadêmica, como ressalta a OMT (1998), o profissional se torna mais capacitado e flexível, sendo capaz de satisfazer as necessidades dos clientes e se sentir motivado e envolvido com a organização em que trabalha. Todavia, nos discursos dos gestores entrevistados, essa relação é bem distinta, como demonstrado abaixo.

A relação entre formação e prática pode ser coisas bem distintas, pois se uma pessoa formada não praticar ela não vai saber lidar com as situações que acontece diariamente no hotel, e às vezes só a formação acaba não sendo suficiente para a carreira de um hoteleiro (GH1.17).

O entrevistado GH2 também concorda com essa ideia, quando diz.

Eu acho que a prática é totalmente diferente, pois na formação você vive em um mundo de teoria onde pensa que tudo é maravilhas, mas na prática é diferente porque temos que se esforçar muito para alcançar objetivos maiores e às vezes esses objetivos não são alcançados porque as oportunidades são mínimas no mercado de trabalho (GH2.17).

Já o gestor $\mathrm{GH} 3$, acha fundamental para o hoteleiro ter essa relação entre formação e prática, como relata abaixo.

O fundamental para um profissional é que ele tenha as duas coisas: teoria e prática, quando ele possui essas duas coisas as chances de ter uma carreira de sucesso aumentam, mas também tem muita gente que consegue se sobressair das dificuldades, pois não é porque uma pessoa que não tem uma formação vai ser um profissional desqualificado, ele pode sim ser um profissional competente e qualificado (GH3.18).

$\mathrm{O}$ entrevistado $\mathrm{GH} 4$ concorda com os gestores $\mathrm{GH} 1$ e $\mathrm{GH} 2$ no sentido de que é diferente essa relação, mas procura se especializar com cursos de capacitação, como enfatiza a seguir:

É diferente pelo fato das vezes terem pessoas que estudam determinado curso e não se identificam, já no meu caso eu me encantei com a prática e estou buscando me especializar na hotelaria com cursos de gestão e, posteriormente, vou buscar outros cursos nesse setor (GH4.19).

Dessa forma, observa-se que o gestor $\mathrm{GH} 3$ acha fundamental essa relação para que o hoteleiro tenha uma carreira de sucesso, já os gestores GH1, GH2 e GH4 acham que a formação e a prática de um hoteleiro são diferentes, pois nem tudo o que se vê na teoria é o que se faz na prática. Outro fator salutar que serviu para verificar essa relação e também a qualidade das pessoas que trabalham na hotelaria no ponto de vista dos gestores foi quando perguntados se a qualificação dos hoteleiros está na sua formação ou na experiência de vida. Então, o gestor GH1 respondeu: "Na minha opinião, na experiência de vida porque atualmente no hotel temos um quadro de funcionários de 23 pessoas e nenhuma delas possui formação, a maioria foi indicado para o hotel por conhecimento" (GH1.20). Concordando com as mesmas ideias, o entrevistado $\mathrm{GH} 2$ descreve abaixo:

Para a região em que estamos situados está na experiência de vida, porque infelizmente aqui na região não se prioriza a formação, uma pessoa formada em hotelaria não tem a valorização que realmente deveria ter, e ainda mais, às vezes acabam perdendo espaço no mercado para pessoas que não têm formação, mas que têm experiência nesse ramo da hotelaria (GH2.20). 
Em contrapartida, o gestor hoteleiro GH3 fala que a qualidade hoteleira está nas duas alternativas, pois um complementa o outro, como pode ser visto a seguir:

Nas duas coisas, mesmo que você tenha experiência de vida e não tenha uma formação acadêmica, não quer dizer que seja melhor nem pior do que alguém, mas é bom estar se capacitando com cursos para que se torne um funcionário melhor do que é no momento, e qualidade não está somente na sua experiência, pois quando tentamos se qualificar independente do meio, aprendemos técnicas que irá nos habilitar para que possamos lidar melhor com as experiências desagradáveis que acontecem no cotidiano da empresa (GH3.20).

Seguindo o mesmo raciocínio do gestor $\mathrm{GH} 3$, o gestor $\mathrm{GH} 4$ concorda que a qualidade está nas duas alternativas, mas que a experiência de vida conta mais, como relata abaixo:

Nas duas alternativas, mas a experiência de vida conta mais porque tomo como base o exemplo da nossa pousada, pois nenhum funcionário que trabalha aqui tem uma formação, tudo o que sabem hoje em dia na hotelaria aprenderam aqui. Os conhecimentos que temos foi passado por outros funcionários que já trabalhavam na pousada, agora é que estamos tentando buscar conhecimentos teóricos para aprimorar nossos conhecimentos práticos (GH4.22).

Portanto, analisa-se que a qualidade dos serviços ofertados não está relacionada só a uma formação, mas sim no conhecimento que um gera para o outro, pois pessoas que já retém conhecimentos e habilidades na área analisada, devido ao tempo em que trabalham nesse segmento, têm a acrescentar para aquelas pessoas que estão se formando em um curso de Hotelaria. Por outro lado, os Bacharéis neste curso tendem a qualificá-la com seus conhecimentos teóricos aprendidos na formação acadêmica. Tal formação do capital humano, de acordo com a Organização Mundial de Turismo (1998), é uma qualidade primordial para que as organizações turísticas se mantenham competitivas e qualificadas no mercado de trabalho. No quadro 2, a seguir, apresentam-se os significados das categorias/competências abordadas no estudo:

Quadro 2: Categorias de uma Gestão por Competências à luz dos resultados obtidos na pesquisa

\begin{tabular}{|c|c|}
\hline CATEGORIAS & SIGNIFICADO \\
\hline $\begin{array}{l}\text { Estratégias Organizacionais com Foco em } \\
\text { Competências }\end{array}$ & $\begin{array}{l}\text { A gestão dos meios de hospedagem dos gestores } \\
\text { entrevistados possui estratégias organizacionais com } \\
\text { foco em competências por meio de experiências } \\
\text { práticas dos seus proprietários e gestores que os } \\
\text { administram, em que dois dos gestores não têm } \\
\text { autonomia para modificá-las, o que pode acabar se } \\
\text { tornando um entrave no desenvolvimento } \\
\text { organizacional dos meios de hospedagem onde foi } \\
\text { realizada a pesquisa. }\end{array}$ \\
\hline $\begin{array}{c}\text { As Competências dos Gestores Hoteleiros do } \\
\text { Brejo Paraibano }\end{array}$ & $\begin{array}{l}\text { Liderança e Relações humanas são palavras que } \\
\text { caracterizam as competências dos gestores hoteleiros } \\
\text { do brejo paraibano, pelo fato de terem uma relação } \\
\text { mais próxima e amigável dos colaboradores, fazendo a } \\
\text { equipe de trabalho ficar mais unida e motivada a } \\
\text { alcançar os objetivos dos meios de hospedagem em que } \\
\text { estão trabalhando. }\end{array}$ \\
\hline $\begin{array}{l}\text { Avaliação dos Gestores sobre as Competências } \\
\text { dos Colaboradores }\end{array}$ & $\begin{array}{l}\text { A avaliação dos gestores sobre as competências dos } \\
\text { colaboradores é fundamental para alcançar resultados } \\
\text { mais satisfatórios. Sendo assim, três dos quatro gestores } \\
\text { avaliam os colaboradores por meio da sua dedicação e o } \\
\text { outro gestor avalia por meio dos cursos que oferece no } \\
\text { hotel. }\end{array}$ \\
\hline Competências Adquiridas por uma Formação & Nenhum dos gestores entrevistados possui formação \\
\hline
\end{tabular}




\begin{tabular}{|c|l|}
\hline Acadêmica em Hotelaria & $\begin{array}{l}\text { em hotelaria, mas um dos quatros falou ter um bom } \\
\text { conhecimento das competências adquiridas por uma } \\
\text { formação acadêmica em hotelaria, qualidades estas } \\
\text { que dá ao profissional hoteleiro a capacidade de } \\
\text { desempenhar qualquer função dentro da hotelaria. }\end{array}$ \\
\hline A Importância do Idioma na Hotelaria & $\begin{array}{l}\text { A hotelaria é um segmento turístico que necessita ter } \\
\text { colaboradores que saibam falar mais de um idioma. No } \\
\text { entanto, nenhum dos entrevistados sabe falar outro } \\
\text { idioma, mas enfatizam que a importância do deste na } \\
\text { hotelaria é essencial para eliminar as dificuldades } \\
\text { existentes neste aspecto. }\end{array}$ \\
\hline Relação entre Formação e Prática de um & $\begin{array}{l}\text { O profissional hoteleiro vivencia duas fases distintas na } \\
\text { hotelaria (o momento da sua formação, em que está } \\
\text { estudando, e na prática, quando vai para o mercado). } \\
\text { Essa relação entre formação e prática de um hoteleiro, } \\
\text { na visão dos gestores entrevistados, era para ser } \\
\text { semelhante, mas não é, pois nem tudo o que se vê na } \\
\text { formação é o que se vivencia na prática. }\end{array}$ \\
\hline
\end{tabular}

Fonte: dados da pesquisa (2016)

\section{CONSIDERAÇÕES FINAIS}

O objetivo deste estudo foi analisar as competências de gestores hoteleiros localizados no brejo paraibano, a partir das que foram expostas no Projeto Político Pedagógico do Curso de Graduação em Hotelaria da Universidade Federal da Paraíba. A análise dos dados identificou as competências exercidas pelos gestores do brejo paraibano que, por meio das mesmas, gerenciam com eficácia os meios de hospedagem em que trabalham. Por mais que os gestores não tenham a formação acadêmica na área de hotelaria, fazem das suas experiências um diferencial para compensar a falta de conhecimentos teóricos, mas têm a consciência de que os conhecimentos práticos e teóricos são importantes na profissão do hoteleiro.

As competências principais destacadas na pesquisa são as de liderança e relações humanas. A avaliação dos colaboradores se faz apenas em critérios mais técnicos de cursos realizados ou sobre a dedicação ao trabalho. Isso mostra o quanto os gestores precisam tomar conhecimento a respeito de uma gestão por competências para que a avaliação seja gerida por habilidades essenciais a cada cargo, aprimorando a qualidade do serviço oferecido pelo hotel. Elas deveriam ser estabelecidas por meio das características que envolvem esse meio de hospedagem como forma de melhor alcançar a satisfação dos turistas.

Doravante, observa-se que o perfil do gestor hoteleiro do brejo paraibano, a partir de suas competências, é diferente do almejado na formação superior em hotelaria. Isso ocorre porque não possuem formação na área e também não apresentam habilidades, como falar outros idiomas, por exemplo. Em contrapartida, por meio de suas experiências na hotelaria, tais gestores desenvolveram competências que os qualificam para gerenciar e os meios de hospedagem. Ressalta-se, entretanto, que o mais adequado para o profissional hoteleiro é possuir conhecimentos teóricos e práticos para que lhes permitam administrar melhor as organizações do segmento hoteleiro.

Vale destacar que é preciso melhorar o elo entre formação e atuação em Hotelaria, sobretudo na valorização de profissionais em cargos de gestão na área e em áreas afins. É fundamental difundir uma gestão atenta ao desenvolvimento de competências, o que 
requer conhecimentos e aprendizados específicos oportunizados na formação que busque compatibilizar as requeridas na realidade da atuação profissional, resultando em um gestor mais preparado em assumir os desafios que lhes compete para o fomento das atividades turísticas.

Portanto, futuros estudos focados no contexto estudado podem enveredar para um olhar analítico das competências dos colaboradores hoteleiros da região do brejo paraibano e em como enxergam as competências dos seus gestores. Além disso, os estudos podem promover a contribuição dos meios de hospedagem aos municípios em que estão situados, para que em conjunto possam alavancar a demanda turística local e, consequentemente, desenvolver a qualidade da hotelaria do brejo paraibano.

\section{REFERÊNCIAS}

BRANDÃO, Hugo Pena; BAHRY, Carla Patrícia. Gestão por competências: métodos e técnicas para mapeamento de competências. Revista do Serviço Público. Brasília 56 (2): 179-194 Abr/Jun 2005.

CARBONE, Pedro Paulo. et. al. Gestão por competência e gestão do conhecimento / Pedro Paulo Carbone, Hugo Pena Brandão, João Batista Diniz Leite, Rosa Maria de Paula Vilhena. 3. Ed. - Rio de Janeiro: Editora FGV, 2009.

CASTELLI, G. Administração hoteleira. 7.ed. Caxias do Sul: Educs, 2000.

CERVO, A. L.; BERVIAN, P. A.; SILVA, R. Metodologia cientifica. 6. ed. São Paulo: Pearson Prentice Hall, 2007.

DUTRA, J. S. Competências: Conceitos e instrumentos para a gestão de pessoas na empresa moderna. São Paulo: Atlas, 2004.

FLEURY, A.; FLEURY, M. T. L. Construindo o conceito de competência. RAC Edição Especial 2001.

HANASHIRO, Darci Mitiko. Gestão do fator humano: uma visão baseada em stakeholders / Darci Mitiko Hanashiro, Laura Menegon Zaccarelli e Maria Luisa Mendes Teixeira; Arilda Schmidt Godoy... [et. al.]. - São Paulo: Saraiva, 2007.

LEME, Rogério. Aplicação prática de gestão de pessoas: mapeamento, treinamento, seleção, avaliação e mensuração de resultados de treinamento. Rio de Janeiro: Qualitymark, 2005.

LEME, Rogério. Seleção e entrevista por competências com o inventário comportamental: guia prático do processo seletivo para redução da subjetividade e eficácia na seleção. Rio de Janeiro: Qualitymark, 2007.

LEVY- LEBOYER, C. Gestión de las competencies. Barcelona: gestión, 1997.

LIMA, T. B.; GOMES, S. L. Os estilos de liderança na gestão hoteleira: um estudo em hotéis da orla de João Pessoa/PB. Organizações em Contexto. Vol. 13. N. 26. São Bernardo do Campo, 2017. 
MASCARENHAS, André Ofenhejm. Gestão estratégica de pessoas: evolução, teoria e crítica / André Ofenhejm Mascarenhas. - São Paulo: Cengage Learning, 2008.

MOLLER, C. O lado humano da qualidade. 12.ed. São Paulo: Pioneira, 1999.

OLIVEIRA, Maria Marly de. Como fazer pesquisa qualitativa. 2a ed. Petrópolis, RJ: Editora Vozes, 2008.

ORGANIZAÇÃO MUNDIAL DO TURISMO. El capital humano e la indústria turística del siglo XXI, 1998.

PRAHALAD, C. K.; HAMEL, G. Competindo pelo futuro. Rio de Janeiro: Campus, 1997.

PROJETO POLÍTICO-PEDAGÓGICO. Projeto Pedagógico do Curso de Bacharelado em Hotelaria da Universidade Federal da Paraíba/Campus IV. Mamanguape, abril de 2006.

RABAGLIO, Maria Odete. Gestão por competência: ferramentas para atração e captação de talentos humanos / Maria Odete Rabaglio. - Rio de Janeiro: Qualitymark, 2008.

RODRIGUES, E. S. Sistema de Inovação Social no Turismo de Areia/PB: um estudo de caso no restaurante Vó Maria. Trabalho de Conclusão de Curso. 53 páginas. Bacharelado em Hotelaria. Universidade Federal da Paraíba, 2017.

RUAS, Roberto. Desenvolvimento de competências gerenciais e contribuição da aprendizagem organizacional. In: FLEURY, Maria Tereza Leme; OLIVEIRA JUNIOR, Moacir de Miranda (Org.). Gestão estratégica do conhecimento: integrando aprendizagem, conhecimento e competência. São Paulo: Atlas, 2001.

RUAS, R. L. Gestão por competências: uma contribuição à estratégia das organizações. In: RUAS, R. L.; ANTONELLO, C. S.; BOFF, L. H. (Org.). Os novos horizontes da gestão: aprendizagem organizacional e competências. Porto Alegre: Bookman, 2005.

SILVA, A. B. A vivência de conflitos entre a prática gerencial e as relações em família. 2005. Tese (Doutorado em Engenharia de Produção). - Universidade Federal de Santa Catarina, Florianópolis, 2005.

SPENCER, L. M.; SPENCER, S. M. Competence at work: models for superior performance. New York: John Wiley \& Sons, 1993.

TRASATTI, Sidney Roberto. Treinamento de Competências Funcionais: Moldando o Futuro Organizacional pelas Pessoas. In: NERI, Aguinaldo (org.). Gestão de RH por Competências e a Empregabilidade. 2.ed. Campinas, SP: Papirus, 2005.

VERGARA, C. S. Métodos de pesquisa em administração. 3. ed. São Paulo: Atlas, 2008. 
AS COMPETÊNCIAS DE GESTORES HOTELEIROS: REFLEXÕES ENTRE FORMAÇÃO E ATUAÇÃO PROFISSIONAL EM HOTELARIA NO BREJO PARAIBANO

VESENTINI, J. W. Sociedade e Espaço: geografia geral e do Brasil. 44a edição. São Paulo: Ática, 2005.

ZARIFIAN, P. Objectif compétence. Paris: Liaisons, 1999.

ZARIFIAN, P. Objetivo competência: por uma nova lógica. 1 Ed. São Paulo: Atlas, 2008.

ZUANETTI, Rose; HARGREAVES, Lourdes; LEE, Renato et al. Qualidade em Prestação de Serviços. 2.ed. Rio de Janeiro: Ed. Senac Nacional, 2001. 